\title{
Precision and additivity of organic matter digestibility obtained via in vitro multi-enzymatic method
}

\author{
C. Álvarez, ${ }^{1,2 *}$ ๑ E. Prestløkken, ${ }^{1} \odot$ N. I. Nielsen, ${ }^{3}$ H. Volden, ${ }^{1,2}$ ๑) G. Klemetsdal, ${ }^{1}$ and M. R. Weisbjerg ${ }^{4} \odot$ \\ ${ }^{1}$ Department of Animal and Aquacultural Sciences, Norwegian University of Life Sciences (NMBU), 1430 Ås, Norway \\ ${ }^{2}$ Tine SA, 1430 Ås, Norway \\ ${ }^{3}$ Livestock Innovation, SEGES, Danish Food and Agricultural Council, 8200 Aarhus, Denmark \\ ${ }^{4}$ Department of Animal Science, AU Foulum, Aarhus University, 8830 Tjele, Denmark
}

\section{ABSTRACT}

The enzymatic digestibility of organic matter (EDOM) method is an in vitro multi-enzymatic method for estimating the organic matter (OM) digestibility of feeds. The EDOM method previously showed high accuracy with in vivo values for compound feeds. The aim of this study was to evaluate the precision of the EDOM method and determine its additivity, compared with the long-assumed additive property of the chemical components of compound feeds. 149 feed samples, 70 commercial compound feeds and 79 associated ingredients, were analyzed in a laboratory (lab1) for OM digestibility measured by EDOM $\left(\mathrm{OMD}_{\mathrm{EDOM}}\right)$ with 2 repetitions separated in time to estimate repeatability. Of the total samples, 49 compound feeds were further analyzed in a commercial laboratory (lab2) for OM$\mathrm{D}_{\text {EDOM }}$ to determine reproducibility. The 49 compounds and their 69 associated ingredients were also analyzed by lab2 for dry matter (DM), ash, crude protein (CP), neutral detergent fiber (NDF), and starch. The EDOM method resulted in an intralaboratory correlation of $98.9 \%$ and an interlaboratory correlation of $92.6 \%$, with no significant mean bias between the 2 laboratories tested. The formulation of compound feeds, total mixed rations, and mixtures in general assumes that their nutrient content can be calculated by adding together the nutrient supply of individual ingredients. This is of great importance in the feed industry for the creation of compound feeds. Additivity of $\mathrm{OMD}_{\mathrm{EDOM}}$ for the compound feed samples was evaluated by comparing the sum of the digestible OM $\left(\mathrm{DOM}_{\mathrm{EDOM}}\right)$ of the ingredients (predicted) with $\mathrm{DOM}_{\mathrm{EDOM}}$ estimated directly in the compound feed (observed). The regression of predicted versus observed showed a coefficient of determination $\left(\mathrm{R}^{2}\right)$ of 0.93 and root mean square

Received October 22, 2019.

Accepted January 7, 2020.

*Corresponding author: clementina.alvarez@tine.no error (RMSE) of $1.07 \%$ of total DM, with no linear bias but with a mean bias ( $0.83 \%$ of DM). Additivity of $\mathrm{CP}$, starch, crude fat, and NDF showed an $\mathrm{R}^{2}$ of 0.95 , $0.98,0.95$, and 0.93 , and RMSE of 1.56, 1.90, 0.39, and $1.46 \%$ of DM, respectively, all presenting linear bias. Crude fat also presented mean bias. Although significant, all linear and mean bias for $\mathrm{DOM}_{\mathrm{EDOM}}$ and chemical components were within the acceptable error limits for declaration of feeds. The results demonstrate the high precision of the EDOM method and its additive property, which is an advantage for the estimation of OM digestibility in compound feeds. Moreover, results of the tests of chemical components confirm their additive property.

Key words: organic matter digestibility, in vitro enzymatic method, compound feed, precision, additivity

\section{INTRODUCTION}

Organic matter digestibility (OMD) is of great importance, as it is the main factor determining the energy value of animal feed (de Boever et al., 1986; Beecher et al., 2015). In vivo determination of OMD of feeds is regarded as the reference value. However, alternative in vitro methods have been developed due to the high levels of labor and costs involved in determining in vivo values. In vitro methods can be divided into rumen liquor digestion (Tilley and Terry, 1963), rumen liquor gas production (Menke et al., 1979), and enzymatic digestion methods (Weisbjerg and Hvelplund, 1993). Due to the high nutritive variability and importance of ruminant diets, most OMD evaluations and comparisons of methods have focused on forage (Barber et al., 1990; Gosselink et al., 2004; Jančík et al., 2011), and limited attention has been placed on concentrate feed ingredients and compound feeds. However, due to the high level of concentrates used in modern dairy production and new feed ingredients, a precise estimation of OMD in concentrate feeds is needed to match the diet supply to energy requirements and thus avoid excess feeding or under-supply. The enzymatic 
digestibility of OM method (EDOM) developed by Weisbjerg and Hvelplund (1993) is a multi-enzymatic method used in Denmark in the feed unit system and in the Nordic Feed Evaluation System (NorFor, Volden, 2011) for estimating the OMD of roughage (Åkerlind et al., 2011). Weisbjerg and Hvelplund (1996) evaluated the accuracy of EDOM (the closeness of the measured values to the in vivo value) on 59 compound feeds from Belgium, Holland, and Denmark, and demonstrated that the method was an accurate estimator for OMD in vivo (correlation of determination, $\mathrm{R}^{2}=0.90$ ). However, little has been studied about the precision of the method (the closeness of the measured values to each other) on compound feeds.

A fundamental assumption in the formulation of diets and compound feeds is that the nutritive values of the ingredients can be added in a simple sum to estimate final concentration in the compound feed. However, this has rarely been studied. The additive relationship of digestibility between ingredients and the compound feed has, to our knowledge, not been studied in dairy nutrition but has been reported in monogastric animals (Angkanaporn et al., 1996; Fan and Sauer, 2002; Xue et al., 2014).

The hypothesis of this study was that the OMD measured by the EDOM method $\left(\mathbf{O M D}_{\mathrm{EDOM}}\right)$ is precise and that $\mathrm{OMD}_{\mathrm{EDOM}}$ measured on individual ingredients is additive in the estimation of $\mathrm{OMD}_{\mathrm{EDOM}}$ of the compound feeds. Therefore, the objective of this study was to evaluate the EDOM method and to aim to establish a relationship between the OMD of individual feed ingredients and the compound feed produced therefrom.

\section{MATERIALS AND METHODS}

\section{Samples for the Estimation of OMD}

In total 149 samples were collected from 6 feed companies from Norway, Denmark, and Sweden. Of these, 70 samples were commercial compound feeds with known compositions, and 79 were the individual concentrate feed ingredients used in the formulation of the compound feeds. All samples were analyzed for $\mathrm{OMD}_{\mathrm{EDOM}}, \mathrm{DM}$, and ash at Aarhus University, Foulum, Denmark (lab1). A subset of 49 compounds feeds were also analyzed for $\mathrm{OMD}_{\mathrm{EDOM}}$ in a commercial laboratory, Eurofins Agro Testing, Vejen, Denmark (lab2).

\section{Estimation of OMD Using the EDOM Method}

For estimation of $\mathrm{OMD}_{\mathrm{EDOM}}$, the method developed by Weisbjerg and Hvelplund (1993) was used with the following adaptation, because 2 of the originally proposed enzymes (gammanase and Novozym 188 from Novozymes Inc., Copenhagen, Denmark) are no longer produced. The sample was milled, and $0.5 \mathrm{~g}$ was weighed into a glass crucible with a filter plate of sintered glass (porosity 1, pore size 90 to $150 \mu \mathrm{m}$ ) and with a rubber stopper at the bottom. After the addition of $30 \mathrm{~mL}$ of pepsin-hydrochloric acid solution (pepsin EC 3.4.23.1, HCl EC 933-977-5, $0.1 \quad N, \mathrm{pH}$ 1.0), the crucible was closed with a top rubber stopper. The crucible was incubated for $24 \mathrm{~h}$ at $40^{\circ} \mathrm{C}$ in a water bath. During incubation, the crucible was shaken twice. Next, the crucible was transferred to an $80^{\circ} \mathrm{C}$ water bath for $45 \mathrm{~min}$. The crucible was then vacuum drained and washed with distilled water to neutralize the residue. With the top and bottom stopper fitted, 30 $\mathrm{mL}$ of enzyme acetate buffer was added $(0.1 \mathrm{~N}, \mathrm{pH} 4.8)$. The enzyme acetate buffer was freshly made at the moment of use. It consisted of $20 \mathrm{~mL}$ of Celluclast $1.5 \mathrm{~L}$ (EC 232-734-4), $10 \mathrm{~mL}$ of Viscozym L (EC 3.2.1.6), $17.0 \mathrm{~mL}$ of Novozym 51054 (EC 253-446-5; all from Novozymes Inc., Copenhagen, Denmark), and $2.175 \mathrm{~g}$ of amyloglycosidase (EC 3.2.1.3, 3,200 U/mL; Megazyme, Bray, Ireland) $0.1 \mathrm{~g}$ of chloramphenicol (EC 200-287$4)$, and $800 \mathrm{~mL}$ of acetate buffer $(\mathrm{pH} 4.8 \pm 0.1)$. The acetate buffer consisted of $8.16 \mathrm{~g}$ of sodium acetate (EC 204-823-8) dissolved in 0.5 L of distilled water and $7.5 \mathrm{~mL}$ of acetic acid (EC 200-580-7, 30\% wt/wt, 5.8 $\mathrm{mol} / \mathrm{L})$, with additional distilled water to make up 1 L. The crucible, with the rubber stoppers, was then re-incubated in the $40^{\circ} \mathrm{C}$ water bath for another $24 \mathrm{~h}$; thereafter the crucible was transferred to a $60^{\circ} \mathrm{C}$ water bath for $19 \mathrm{~h}$. The crucible was shaken twice during each incubation. After the stoppers were removed, the crucible was vacuum drained and washed with boiling distilled water twice, then twice with $20 \mathrm{~mL}$ of acetone (EC 200-662-2). The first acetone wash was performed with the bottom plug fit for 5 min to ensure successful extraction. Finally, the crucible was dried for $16 \mathrm{~h}$ at $103^{\circ} \mathrm{C}$ and, after being weighed, incinerated at $525^{\circ} \mathrm{C}$ and re-weighed to determine the ash residue. Each sample was analyzed twice as true replicates with at least 1 wk between batches.

\section{Samples for Evaluation of Additivity of OMD and Chemical Components}

The subset of 49 compounds and the corresponding 69 ingredient samples, analyzed for $\mathrm{OMD}_{\mathrm{EDOM}}$ in lab2, were also analyzed in lab2 for nitrogen according to the Dumas method (Dumas, 1831), and CP was estimated as $\mathrm{N} \times 6.25$, crude fat (CFat) as petrol ether extract after $\mathrm{HCl}$ hydrolysis according to EU 152/2009 (European Commission, 2009), NDF (ash corrected) via the amylase-treated NDF method (Mertens et al., 2002), starch via the enzymatic method (Åkerlind et 
al., 2011) using heat-stable amylase and, glucose using a YSI 2900D apparatus (Yellow Springs, OH). Ingredients with a maximum inclusion lower than $2 \%$ of total DM in compound feed samples, minerals, and vitamins were not analyzed, and values from NorFor Feed Table were used. For many ingredients, several samples were included, corresponding to the different feed companies. Ingredient samples from the same feed company could be included in several compound feeds from that company. Table 1 shows a summary of samples per ingredient and numbers of compound feeds formulated with each ingredient. Digestible OM on DM basis $\left(\mathbf{D O M}_{\mathrm{EDOM}}\right)$ was calculated based on $\mathrm{OMD}_{\mathrm{EDOM}}$ and $\mathrm{OM}$ (in DM) concentration in all the samples. This parameter was used to evaluate the additivity of OM$\mathrm{D}_{\text {EDOM }}$.

\section{Statistical Analysis}

All statistical analysis was performed using R software (version 3.6.0, R Core Team, 2019).
Precision of the EDOM Method. Following analysis according to Bartlett and Frost (2008), repeatability of the EDOM method was evaluated via OM$\mathrm{D}_{\mathrm{EDOM}}$ through intraclass correlation (ICC) and repeatability coefficient (rcoef). The rcoef is the standard deviation (SD) between 2 measurements on the same sample $\left(\sqrt{2} \times 1.96 \times \mathrm{SD}_{\text {within_sample }}\right)$. The ICC was estimated using the rpt function from the rptR package and the linear mixed model method (Stoffel et al., 2017), considering the sample as random effect. The $\mathrm{OMD}_{\mathrm{EDOM}}$ of 149 samples measured at lab1 was used for the calculation, with 2 repetitions per sample, 298 observations in total.

Reproducibility was considered as the agreement of measurements between laboratories. The $\mathrm{OMD}_{\mathrm{EDOM}}$ of the 49 compound feeds analyzed in the 2 different laboratories (lab1 and lab2) was used, accounting for a total of 98 observations (49 observations per laboratory). Each observation was the average of 2 repetitions within the same laboratory. Agreement between the 2 laboratories was inferred using the Bland-Altman plot,

Table 1. Summary of the ingredient composition of the 49 studied compound feeds (minimum and maximum share in \% of total DM) and number of samples per ingredient; individual ingredients are shown only if present in a compound feed at more than $10 \%$ of total DM

\begin{tabular}{|c|c|c|c|c|}
\hline \multirow[b]{2}{*}{ Ingredient } & \multirow{2}{*}{$\begin{array}{l}\text { No. of samples } \\
\text { per ingredient }\end{array}$} & \multicolumn{2}{|c|}{$\begin{array}{l}\text { Share of compound feeds }{ }^{1} \\
\text { ( } \% \text { of DM) }\end{array}$} & \multirow{2}{*}{$\begin{array}{l}\text { Compound } \\
\text { feeds (no.) }\end{array}$} \\
\hline & & Min. & Max. & \\
\hline Soybean meal & 5 & 0.6 & 40.4 & 32 \\
\hline Wheat & 5 & 1.9 & 31.3 & 31 \\
\hline Sugar beet pulp & 4 & 1.4 & 29.1 & 29 \\
\hline Rapeseed meal & 3 & 3.2 & 38.4 & 28 \\
\hline Rapeseed cake & 4 & 2.0 & 49.5 & 27 \\
\hline Wheat bran & 5 & 2.0 & 26.8 & 27 \\
\hline Barley & 5 & 1.9 & 48.2 & 26 \\
\hline Distillers grains & 2 & 2.1 & 35.7 & 23 \\
\hline Oats & 4 & 1.0 & 24.6 & 22 \\
\hline Rye & 1 & 2.8 & 31.1 & 19 \\
\hline Sunflower meal & 2 & 1.7 & 10.4 & 17 \\
\hline Soybean hulls & 1 & 2.2 & 16.4 & 12 \\
\hline Maize & 3 & 1.9 & 14.9 & 11 \\
\hline Citrus pulp & 1 & 2.0 & 15.7 & 10 \\
\hline Soypass $^{3}$ & 3 & 0.6 & 32.4 & 9 \\
\hline Maize gluten meal & 2 & 1.0 & 22.7 & 8 \\
\hline ExPro $^{4}$ & 1 & 10.7 & 51.1 & 8 \\
\hline Malt sprout $^{5}$ & 2 & 1.3 & 12.1 & 6 \\
\hline Wheat middling & 1 & 5.0 & 14.9 & 5 \\
\hline Palm kernel cake & 2 & 2.2 & 12.5 & 4 \\
\hline Alkaline barley ${ }^{6}$ & 1 & 19.5 & 19.5 & 1 \\
\hline Other $^{7}$ & 12 & $<10$ & $<10$ & 49 \\
\hline Total & 69 & & & 49 \\
\hline
\end{tabular}

${ }^{1}$ Minimum and maximum percentages of inclusion in the compound feeds containing the ingredient.

${ }^{2}$ Number of compound feed samples that include the ingredient.

${ }^{3}$ Rumen-protected soybean meal (Denofa, Gamle Fredrikstad, Norway).

${ }^{4}$ Steam-processed non-GMO rapeseed meal (AAK AB, Malmö, Sweden).

${ }^{5}$ By-product of malting industry.

${ }^{6}$ Barley treated with urea and reaction promoters (Norgesfor AS, Oslo, Norway).

${ }^{7}$ Ingredients with a maximum inclusion lower than $10 \%$ of DM. 
as suggested by Bartlett and Frost (2008), and the differences in mean between laboratories was evaluated using the $t$-test, with a level of significance of 0.05 . The interlaboratory coefficient (ILC) was also estimated using the rptR package, with sample as random effect.

Additive Property. The additive property was examined for the 49 compound feeds containing the 69 corresponding ingredients. The relationship between the compound feed and their ingredients was tested using the following 2 approaches.

Pure additivity (Model A): This model is based on the hypothesis that individual feedstuffs can be added linearly to achieve a certain value in the final compound feed, called additivity. For a given nutrient, additivity was evaluated by comparing the nutrient concentration (\% of DM), measured directly in the compound feed sample, with the value calculated by the sum of ingredients, considering the ingredients proportion in the compound feed (weighted sum of ingredients). Additivity was analyzed for $\mathrm{DOM}_{\mathrm{EDOM}}$, $\mathrm{CP}$, starch, CFat, and NDF. Model A for all parameters was evaluated by regressing the predicted weighted sum of ingredients against the observed values measured directly in the compound samples and analyzing the $\mathrm{R}^{2}$ and root mean square error (RMSE). Moreover, the predicted values were regressed on residuals. Predicted values were centered around the mean, making the slope and the intercept independent and orthogonal, for mean and linear bias evaluation, respectively (St-Pierre, 2003).

Ingredient effect (Model $\mathbf{B}_{i} ; i=1,2, \ldots$ ): We developed Model $\mathrm{B}_{i}$ assuming that not only was the $\mathrm{DOM}_{\mathrm{EDOM}}$ of the compound feed explained through additivity but also that it could include effects of specific ingredients and interactions between them. Principal component analysis was used to identify possible interactions via the correlation matrix between the contribution of $\mathrm{DOM}_{\mathrm{EDOM}}$ of each ingredient in the compound feeds. This means that the $\mathrm{OMD}_{\mathrm{EDOM}}$ of the ingredient and its proportion of inclusion were both taken into consideration. If 2 or more ingredients were assigned to the same principal component (PC), the individual ingredients, as well as the interaction, were included as additional variables to model $\mathrm{A}$; these models were denoted $\mathrm{B}_{i}(i=1$ to $\mathrm{n}$ ), where $i$ was the number assigned to a new model when a correlation between ingredients detected in the $\mathrm{PC}$ was significant $(P<0.05)$. Principal component analysis was performed using the pca function from package stats (R Core Team, 2019).

Models $\mathrm{A}$ and $\mathrm{B}_{i}$ were estimated via linear models using the linear model function $(\mathrm{lm})$ from package stats (R Core Team, 2019). Effect of company was evaluated by including company as random effect and comparing fit with the models including only fixed effects of RMSE and Bayesian information criterion statistic (BIC). Mixed models were created using the lmer function in the lme4 package (Bates et al., 2015). The level of significance for inclusion of an effect in the model was 0.05. Model fit comparison was performed using BIC statistics. The prediction ability of the models was obtained through the predicted correlation coefficient $\left(\bar{R}^{2}\right)$, this being the ratio between the predicted sum of squares, calculated using the leave-one-out technique (predicted residual error sum of squares, PRESS), according to Allen (1974), and the total sum of squares.

\section{RESULTS}

Table 2 shows the summary of the $\mathrm{OMD}_{\mathrm{EDOM}}$ for the 149 samples (70 compound feeds and 79 ingredients) used to estimate repeatability and reproducibility. Chemical compositions and $\mathrm{OMD}_{\mathrm{EDOM}}$ of the $118 \mathrm{sam}-$ ples (49 compound feeds and 69 ingredients) are also shown in Table 2. The range of all nutrients was larger for the ingredient samples than for the compound feeds. Compound feeds consisted of both protein and energy supplements; 14 of the 49 compound feeds consisted of more than $25 \%$ of CP in DM and could be attributed as protein supplements, and almost half of the compound feed samples (24 compound samples) contained more than $25 \%$ starch.

Shares of the ingredients constituting the 49 compound feeds are summarized in Table 1 . Soybean meal was the most frequent ingredient, included in $32 \mathrm{com}-$ pound feeds (32), although its concentration varied considerably, from 0.6 to $40.4 \%$ of DM. Other frequently used protein-rich ingredients included rapeseed meal (28), rapeseed cake (27), and wheat bran (27). Cereals wheat (31), barley (26), oats (22), and rye (19) were the most frequent carbohydrate sources. Beet pulp was the most-used fiber-rich ingredient (29).

\section{Repeatability}

The ICC from the 149 samples and 298 observations was 0.989 . This means that $98.9 \%$ of the variation between the measurements was attributable to genuine differences between the feed samples, with the $1.1 \%$ remaining variance being due to errors in measurements. The estimated $\mathrm{SD}$ of $\mathrm{OMD}_{\mathrm{EDOM}}$ within samples was $0.8 \% \mathrm{OM}$, and the corresponding SD between samples was $7.7 \%$ OM. The estimated rcoef was $2.2 \% \mathrm{OM}$ with a $95 \%$ confidence interval (the maximum future difference of $\mathrm{OMD}_{\mathrm{EDOM}}$ between 2 measurements in $95 \%$ of cases). 


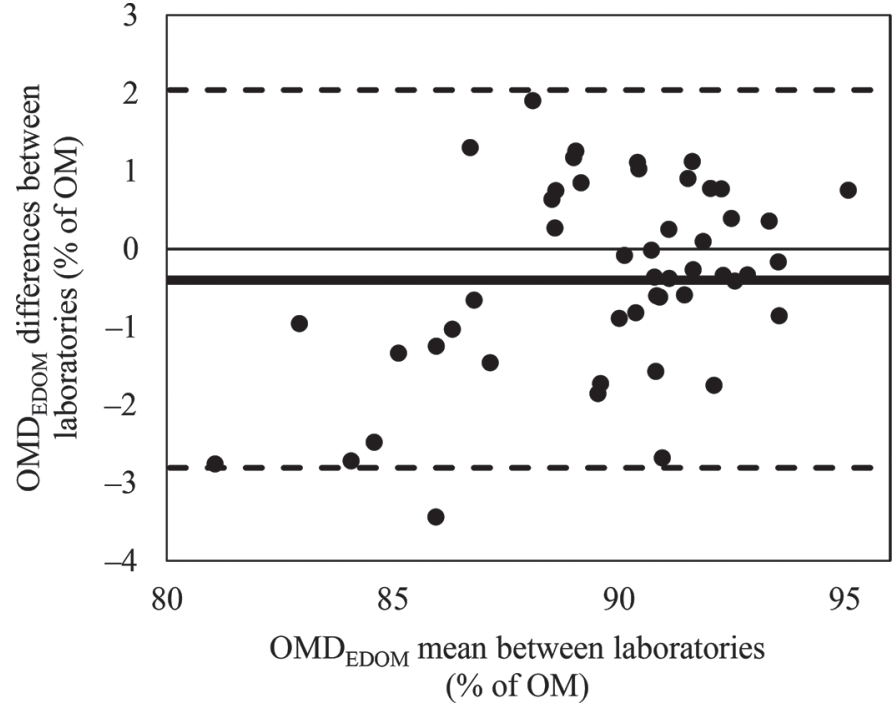

Figure 1. Differences in measures between the 2 laboratories of OM digestibility measured by enzymatic digestibility of OM (EDOM) method $\left(\mathrm{OMD}_{\mathrm{EDOM}}\right)$ against the mean value. Solid line $=$ mean differences between laboratories; upper dashed line $=$ mean $+1.96 \mathrm{SD}$; lower dashed line $=$ mean $-1.96 \mathrm{SD}$, with $95 \% \mathrm{CI}$.

\section{Reproducibility}

Reproducibility of the method measured by ILC was 0.926 , meaning that $7.4 \%$ of the variation of $\mathrm{OMD}_{\mathrm{EDOM}}$ was due to measurement errors. The relationship between the 2 laboratories can be seen in the Bland-Altman plot (Figure 1). The estimated OMD mean of the differences between lab1 and lab2 was $-0.4 \% \mathrm{OM}$, suggesting that, on average, lab2 provided higher values than lab1 but that this difference was not significant $(P=0.57)$. The absolute maximum difference in OMD between future measurements in these 2 laboratories will be $2.8 \% \mathrm{OM}$ in $95 \%$ of cases (lower limit, Figure 1).

\section{Relation Between Ingredients and Compound Feeds: Additivity}

The effect of company only improved model fit for starch. Thus company effect was not included, and only fixed effects were considered in the models.

Additivity of the method was evaluated through $\mathrm{DOM}_{\mathrm{EDOM}}$. Our $\mathrm{DOM}_{\mathrm{EDOM}}$ regression showed an $\mathrm{R}^{2}$ of 0.93 and RMSE of $1.07 \%$ DOM between $\mathrm{DOM}_{\mathrm{EDOM}}$ values measured directly in the compound feeds (observed) and those calculated through addition of the ingredients (predicted; Figure 2a). The residual analysis (Figure $2 \mathrm{~b}$ ) showed a mean bias $(P<0.001)$, so that the added $\mathrm{DOM}_{\mathrm{EDOM}}$ of the ingredients tended to underpredict $\mathrm{DOM}_{\mathrm{EDOM}}$ values of the compound feed by 0.83 percentage points on average. We found no linear bias $(-0.01, P=0.80)$.

The CP regression (Figure 3a) showed an $\mathrm{R}^{2}$ of 0.95 and RMSE of $1.56 \% \mathrm{CP}$ in DM between observed and predicted values. The residual analysis (Figure $3 \mathrm{~b}$ ) showed no mean bias $(0.26, P=0.25)$, but a linear bias was revealed $(-0.07, P=0.02)$. However, the bias was only 0.82 percentage points at the minimum predicted value and -0.92 percentage points at the maximum.

Starch estimated by ingredient addition (Figure 4a) showed an $\mathrm{R}^{2}$ with the starch analyzed in the compound feed of 0.98 and RMSE of $1.90 \%$ starch in DM. Residual analysis (Figure $4 \mathrm{~b})$ showed no mean bias $(-0.34 P=$ $0.23)$ but did show a linear bias $(-0.04, P=0.04)$. Biases at the minimum and maximum predicted values were 0.50 and -1.2 percentage points, respectively.

For the CFat analysis, 2 compound feeds were excluded as outliers. Crude fat estimated by additivity and CFat measured directly in the compound feed sample presented an $\mathrm{R}^{2}$ of 0.95 and RMSE of $0.39 \%$ CFat in DM (Figure 5a). The residual analysis (Figure

Table 2. Summary statistics for the chemical composition of compound feeds and their ingredients

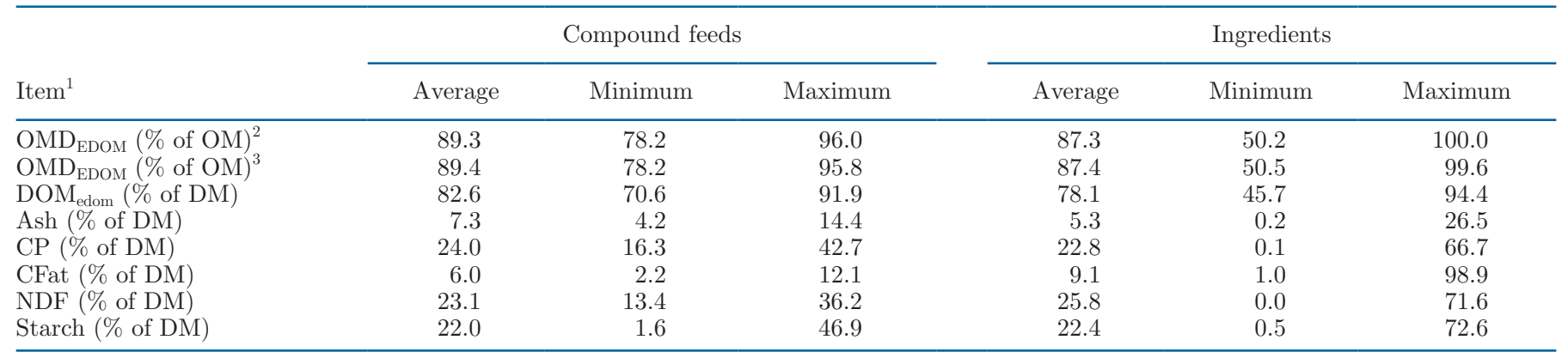

${ }^{1} \mathrm{OMD}_{\mathrm{EDOM}}=\mathrm{OM}$ digestibility by enzymatic digestibility of OM $(\mathrm{EDOM})$ method; $\mathrm{DOM}_{\mathrm{EDOM}}=$ digestible OM by EDOM method; CFat $=$ crude fat.

${ }^{2}$ Feed $\mathrm{n}=70$; ingredient $\mathrm{n}=79$. Used for calculation of repeatability [analyzed in lab1 (Aarhus University, Foulum, Denmark)].

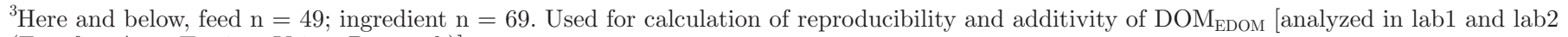
(Eurofins Agro Testing, Vejen, Denmark)]. 

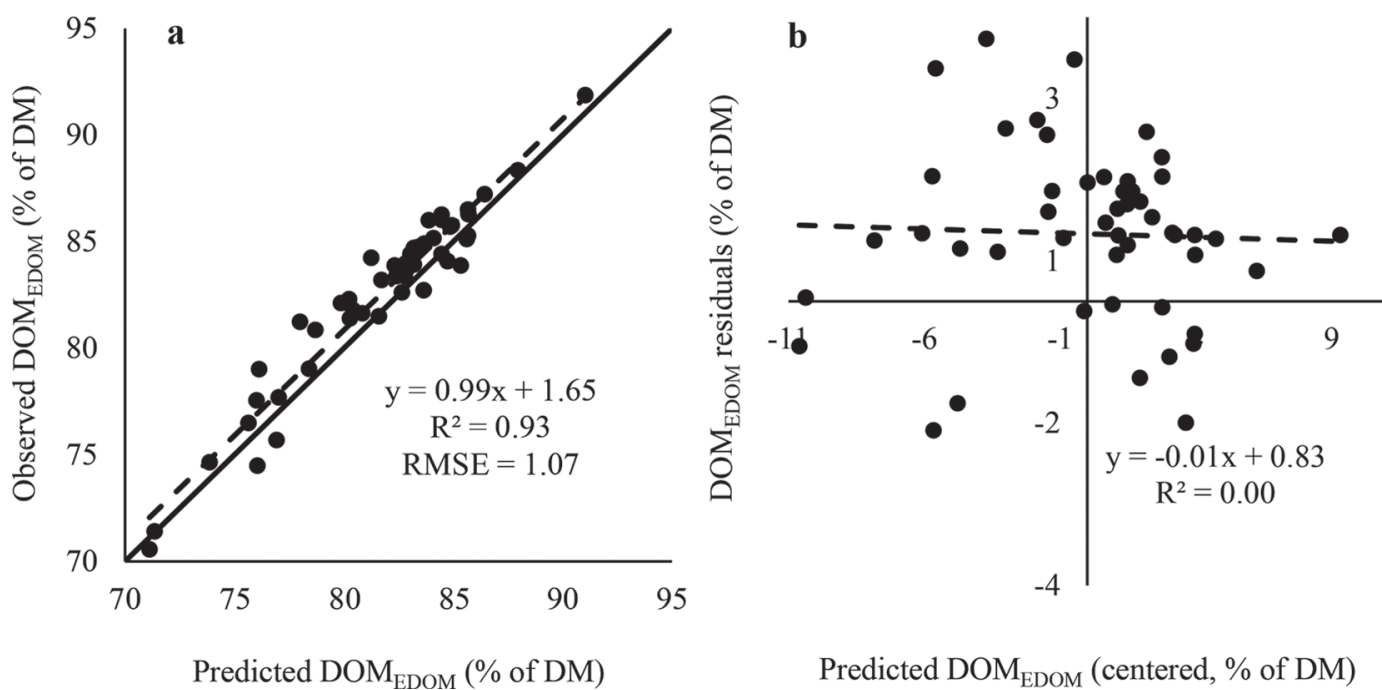

Predicted DOM $\mathrm{EDOM}$ (centered, \% of DM)

Figure 2. (a) Regression between digestible $\mathrm{OM}$ on $\mathrm{DM}$ basis $\left(\mathrm{DOM}_{\mathrm{EDOM}}\right)$ calculated by the weighted sum of ingredients (Predicted $\mathrm{DOM}_{\mathrm{EDOM}}$ ) and $\mathrm{DOM}_{\mathrm{EDOM}}$ measured in compound feeds (Observed $\mathrm{DOM}_{\mathrm{EDOM}}$ ). (b) Residual analysis of the relationship between $\mathrm{DOM}$ estimated by weighted sum of ingredients (Predicted $\mathrm{DOM}_{\mathrm{EDOM}}$ ), centered to the mean, and $\mathrm{DOM}_{\mathrm{EDOM}}$ measured in compound feed (Observed $\left.\mathrm{DOM}_{\mathrm{EDOM}}\right) . \mathrm{DOM}_{\mathrm{EDOM}}$ residuals $=$ Predicted $\mathrm{DOM}_{\mathrm{EDOM}}-$ Observed $\mathrm{DOM}_{\mathrm{EDOM}} \cdot \mathrm{RMSE}=$ root mean square error.

$5 \mathrm{~b})$ showed that the predicted values overestimated the CFat values in the compound feed (mean bias $-0.22, P$ $<0.001)$, and the difference increased with increasing values of CFat (linear bias $-0.11, P<0.001$ ). Bias at the minimum predicted value was -0.08 percentage points and 0.56 at the maximum.

The NDF regression (Figure 6a) showed an $\mathrm{R}^{2}$ between the predicted and observed values of 0.93 and RMSE of $1.46 \%$ NDF in DM. The residual analysis (Figure $6 \mathrm{~b})$ showed no mean bias $(0.25, P=0.25)$ but a linear bias $(-0.12, P=0.001)$. Bias at the minimum was 1.79 percentage points and at the maximum predicted value was -2.01 percentage points.

Table 3 shows the proportion of the 49 compound feed samples that, as predicted by additivity, lay in the $2 \%$ and $5 \%$ range for error. The highest proportion of predicted values below $2 \%$ error was for $\mathrm{DOM}_{\mathrm{EDOM}}$ : $85.7 \%$ of the samples (42 samples) fell inside the $2 \%$ error range, and $100 \%$ lay in the $5 \%$ error range. Starch resulted in the lowest percentage of samples in the $2 \%$
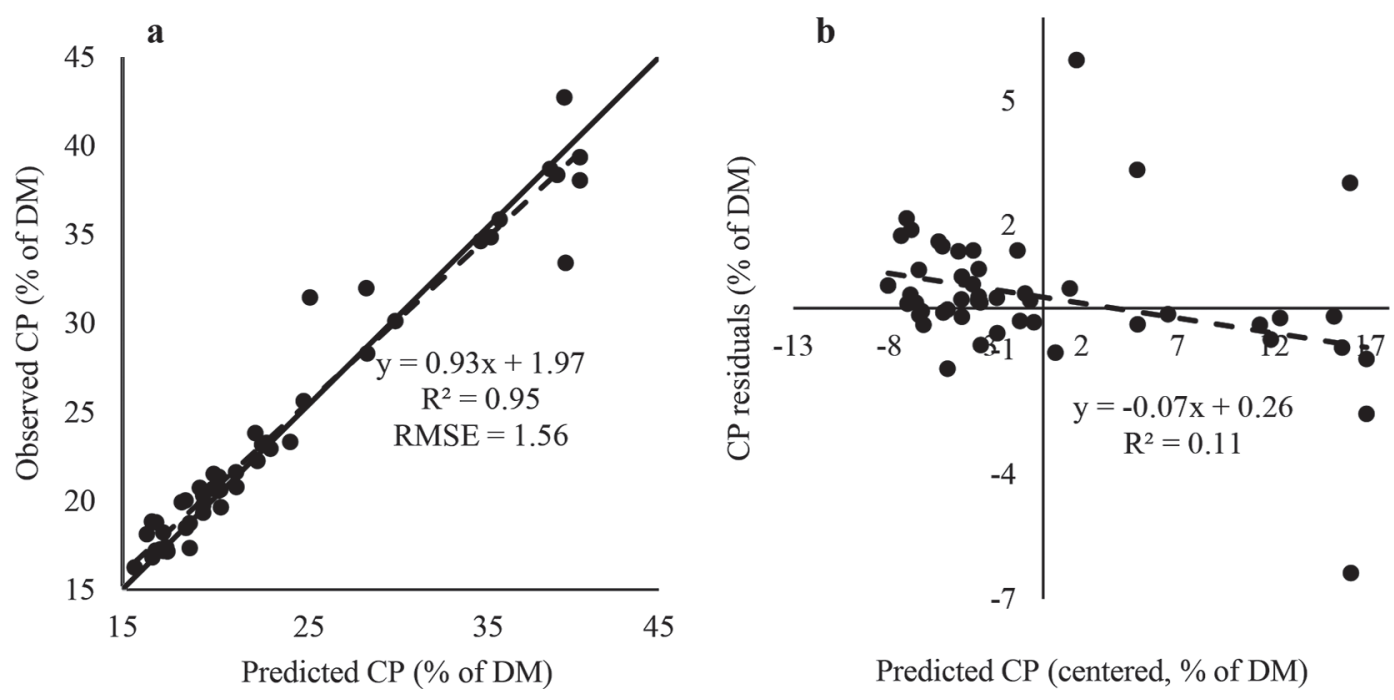

Predicted CP (centered, \% of DM)

Figure 3. (a) Regression between $\mathrm{CP}$ calculated by weighted sum of ingredients (Predicted CP) and $\mathrm{CP}$ measured in compound feeds (Observed CP). (b) Residual analysis of the relationship between CP estimated by weighted sum of ingredients (Predicted CP), centered to the mean, and CP measured in compound feed (Observed CP). CP residuals = Predicted CP - Observed CP; RMSE $=$ root mean square error. 

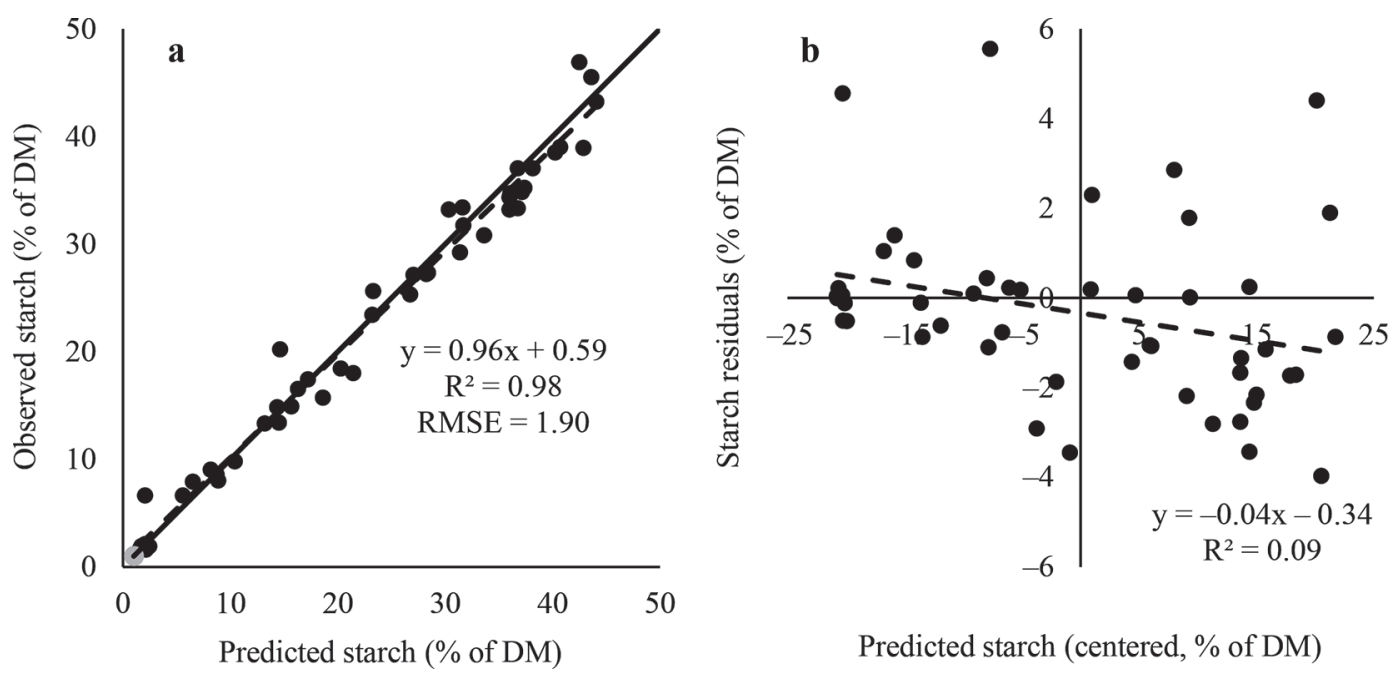

Predicted starch (centered, \% of DM)

Figure 4. (a) Regression between starch calculated by weighted sum of ingredients (Predicted starch) and starch measured in compound feeds (Observed starch). (b) Residual analysis of the relationship between starch estimated by weighted sum of ingredients (Predicted starch), centered to the mean, and starch measured in compound feed (Observed starch). Starch residuals = Predicted starch - Observed starch; RMSE $=$ root mean square error.

error range $(26.5 \%, 13$ samples) and in the $5 \%$ error range $(46.5 \%, 23$ samples). For CP, CFat, and NDF concentrations in DM, more than $50 \%$ of the samples lay within the $5 \%$ error range.

\section{Relation Between Ingredients and Compound Feeds: Ingredient Effect for DOM}

The principal component analysis showed that the first 6 principal components (PC1 to PC6) explained $78 \%$ of the variance, and the correlation matrix of these
PC was analyzed to detect the effects of the ingredients. Table 4 shows nested models, from the reduced model showing simple additivity (Model A), to model $\mathrm{B}_{3}$, showing all the identified effects of ingredients (full model). The correlation matrix of PC1 showed a correlation between soybean meal, wheat, and barley. Model $\mathrm{B}_{1}$ was created based on PC1 and showed an interaction only between soybean meal and wheat $(P=$ $0.03)$ and an effect of wheat as an independent variable $(P=0.05)$, although soybean meal and barley had no effect as independent variables $(P=0.17$ and $P=0.13$,
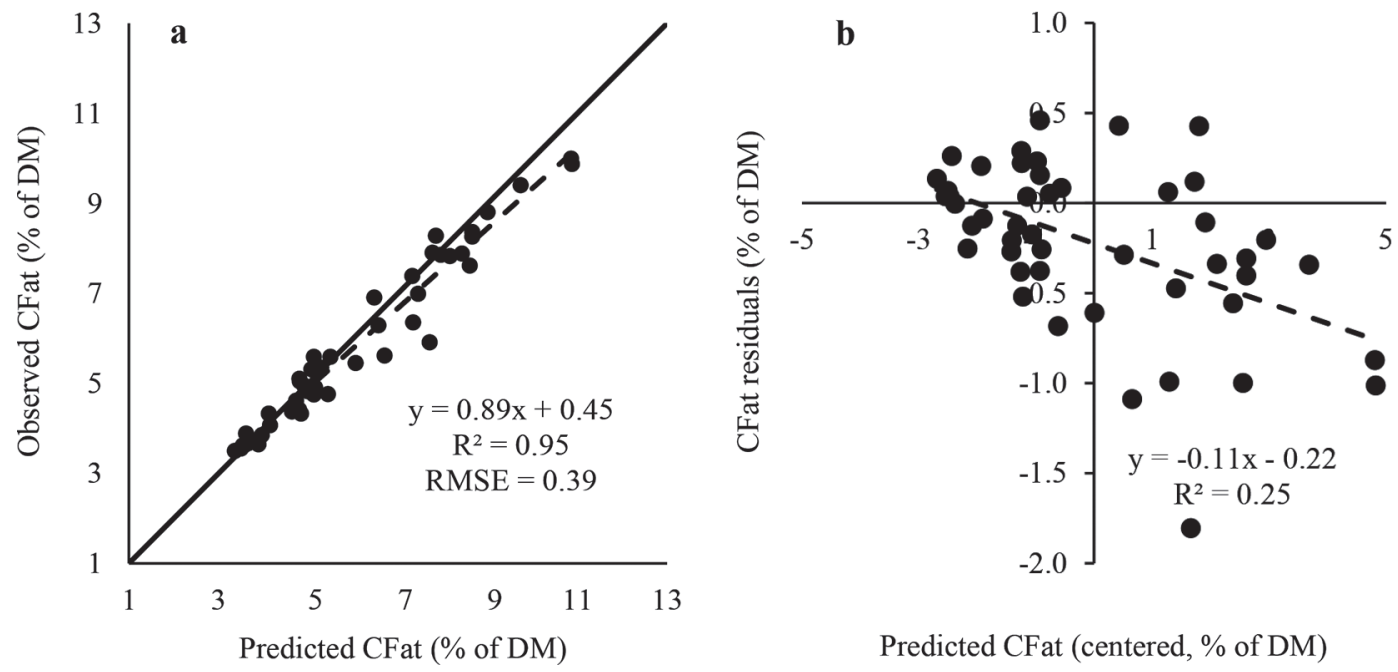

Predicted CFat (centered, \% of DM)

Figure 5. (a) Regression between crude fat (CFat) calculated by weighted sum of ingredients (Predicted CFat) and CFat measured in compound feeds (Observed CFat). (b) Residual analysis of the relationship between CFat estimated by weighted sum of ingredients (Predicted CFat), centered to the mean, and CFat measured in compound feed (Observed CFat). CFat residuals = Predicted CFat - Observed CFat; $\mathrm{RMSE}=$ root mean square error. 
Table 3. Number and percentage of predicted digestible OM, $\mathrm{CP}$, crude fat (CFat), NDF, and starch values by weighted sum of ingredients (additivity) within 2 and $5 \%$ error ranges

\begin{tabular}{|c|c|c|c|c|}
\hline \multirow[b]{3}{*}{ Item } & \multicolumn{4}{|c|}{ Error range ${ }^{1}$} \\
\hline & \multicolumn{2}{|c|}{$2 \%$} & \multicolumn{2}{|c|}{$5 \%$} \\
\hline & $\mathrm{N}$ & $\%$ & $\mathrm{~N}$ & $\%$ \\
\hline$\overline{\mathrm{DOM}}_{\mathrm{EDOM}}{ }^{2}(\%$ of $\mathrm{OM})$ & 42 & 85.7 & 49 & 100.0 \\
\hline $\mathrm{CP}(\%$ of $\mathrm{DM})$ & 25 & 51.0 & 35 & 71.4 \\
\hline CFat ( $\%$ of DM) & 14 & 29.8 & 27 & 57.4 \\
\hline NDF (\% of DM) & 9 & 18.4 & 26 & 53.1 \\
\hline Starch (\% of DM) & 13 & 26.5 & 23 & 46.9 \\
\hline
\end{tabular}

${ }^{1} \mathrm{~A}$ compound feed was included in the $2 \%$ level if the predicted value, by additivity, fell within the range of the observed value $\pm 2 \%$. A compound feed was included in the $5 \%$ level if the predicted value, by additivity, fell within the range of the observed value $\pm 5 \%$. $\mathrm{N}=$ number of samples within the error range; $\%=$ proportion of samples within the error range (49 total compound feeds).

${ }^{2} \mathrm{DOM}_{\mathrm{EDOM}}=$ digestible OM by enzymatic digestibility of OM (EDOM) method.

respectively). The next $\mathrm{PC}(\mathrm{PC} 2)$ showed a correlation between rapeseed cake, soybean meal, and barley, but neither these ingredients nor their interactions were significant; thus no model was created. We found that PC3 showed a correlation between wheat, rye, and rapeseed meal. Model $\mathrm{B}_{2}$, based on $\mathrm{PC} 3$, showed a triple interaction between rapeseed meal, rye, and wheat $(P$ $=0.02)$, as well as effects of rapeseed meal $(P=0.02)$ and soybean meal $(P=0.04)$. In $\mathrm{PC} 4$ we discovered a correlation between wheat, soybean meal, and oats, but no effect of the ingredients nor of their interaction was found when these variables were tested in the model.
We found that PC5 showed a correlation between wheat and sugar beet pulp. Based on PC5, model $\mathrm{B}_{3}$ showed an interaction between wheat and sugar beet pulp $(P=$ 0.02 ) as well as an effect of sugar beet pulp as an independent variable $(P=0.03)$. Both variables were included to create $\mathrm{B}_{3}$. Finally, PC6 presented a correlation between wheat and rye, but these variables were already taken into consideration in $\mathrm{B}_{2}$. All the models presented a nonsignificant intercept, and all the variables included in the regression had a significance of at least $P<0.05$. The $\mathrm{R}^{2}$ was highest for model $\mathrm{B}_{3}(0.96)$ and lowest for model A (0.93). However, when analyzing the $\bar{R}^{2}$ differences between model $\mathrm{A}$ and $\mathrm{B}_{3}$, this decreased from $3 \%$ to $1 \%$. The BIC was lowest for model A (157) and highest for model $\mathrm{B}_{1}(165)$.

\section{DISCUSSION}

The EDOM method was developed for concentrates and is accepted by NorFor for estimating the OMD of forages (Åkerlind et al., 2011). However, little has been reported regarding the use of this method on compound feeds. With the present study, we intended to evaluate the precision of the EDOM method through calculation of repeatability and reproducibility. Moreover, we examined whether the relationship between ingredients and the compound feed was purely additive or whether, in addition, the effects of ingredients and their interactions should be considered when formulating compound feeds. The additive relationship was also examined for the traditional chemical parameters $(\mathrm{CP}, \mathrm{CFat}$, starch,
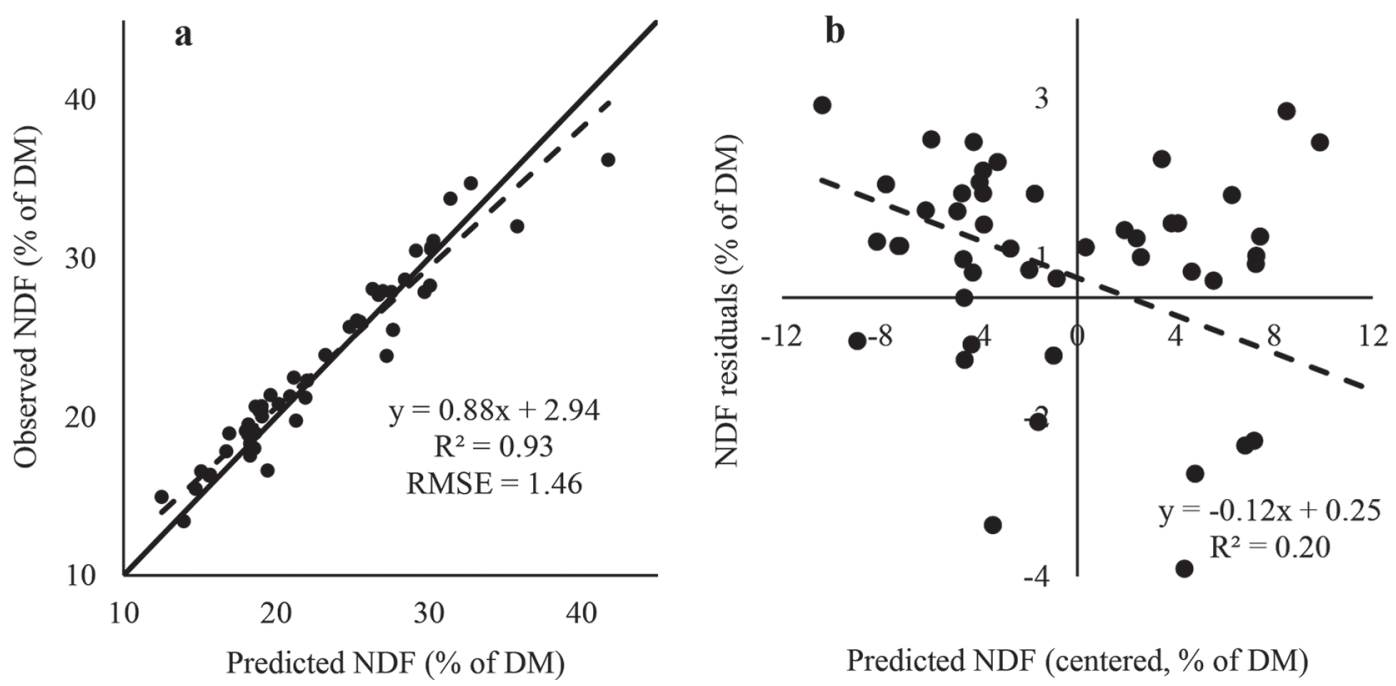

Predicted NDF (centered, \% of DM)

Figure 6. (a) Regression between NDF calculated by weighted sum of ingredients (Predicted NDF) and NDF measured in compound feeds (Observed NDF). (b) Residual analysis of the relationship between NDF estimated by weighted sum of ingredients (Predicted NDF), centered to the mean, and NDF measured in compound feed (Observed NDF). NDF residuals = Predicted NDF - Observed NDF; RMSE $=$ root mean square error. 
and NDF), which have long been assumed to be additive, although published evidence is difficult to find.

The high correlation between $\mathrm{OMD}_{\mathrm{EDOM}}$ and in vivo values has been demonstrated (Weisbjerg and Hvelplund, 1996), and the EDOM method showed better performance than the gas production (Palić and Leeuw, 2009) and rumen fluid methods (Søegaard et al., 2001; Weisbjerg et al., 2007). Thus, EDOM could have an advantage over other in vitro methods, as the various steps could better mimic animal digestion. This high accuracy, meaning close measurements to the reference value (in vivo), is a desirable characteristic in all laboratory methods. Nevertheless, precision-here meaning how close repeated measures are to each other - is also fundamental for a method to be adoptable in practice.

The large variation of in $\mathrm{OMD}_{\mathrm{EDOM}}$ and chemical components in our data set represent the variations seen in the Scandinavian feed industry. This is also reflected by the frequent use of soybean meal and rapeseed byproducts as main protein sources and cereals as starch sources. The achieved variations were of great importance for our study, as these allowed us to evaluate the precision of $\mathrm{OMD}_{\mathrm{EDOM}}$ in a large range of values and evaluate how additivity performs in different nutrient concentrations. Additionally, if our results show that the EDOM method is precise, this will support the easy adoption of this method in more countries.

\section{Precision of the EDOM Method}

The results of this study indicate that the EDOM method is precise enough for the analysis of OMD in compound feeds. Repeatability defines the correlation between repeated measures of the same sample using the same measurement procedure, laboratory team, and experimental setup (JCGM, 2012). In other words, repeatability measures the agreement between repetitions in the same laboratory. The high ICC (98.9\%) and low expected difference of $\mathrm{OMD}_{\mathrm{EDOM}}$ between future repetitions ( $\mathrm{rcoef}=2.2 \% \mathrm{OM}$ ) showed that the EDOM method was highly repeatable within the laboratory. Higher repeatability of $\mathrm{OMD}_{\mathrm{EDOM}}$ of this study agrees with lower variation of $\mathrm{OMD}_{\mathrm{EDOM}}$ between measurements on forage samples compared with OMD measured via a rumen fluid method (Tilley and Terry, 1963), 0.63 and 1.87\% OM (Søegaard et al., 2001), and 0.7 and $2.4 \%$ OM (Weisbjerg et al., 2007), respectively. A similar effect was found using another enzymatic method, when digestibility of compound feeds was evaluated by de Boever et al. (1986). The rumen fluid method showed higher OMD variation between repetitions $(1.1 \% \mathrm{OM})$ compared with a pepsin cellulase method developed by Iowerth et al. (1975) and adapted for compound feeds by Aufrère and Michalet-Doreau (1983), 0.69 and $0.84 \%$ OM for the 2 different cellulase enzymes tested. This pepsin cellulase method has similarities to the EDOM method.

Although repeatability is a necessary parameter to evaluate the precision of a method, it should not be viewed as a solitary result, as the variability between laboratories can be greater than the variability within one laboratory (Parker et al., 2018). Reproducibility of $100 \%$ is desirable, meaning that different laboratories obtain the same result with the same method using different tools and operators (JCGM, 2012). The ILC in this study (92.6\%) was lower than ICC (98.9\%). This was expected, because more sources of variation are involved, such as different technicians and equipment available in each laboratory (Taylor and Kuyatt, 1994). This study included only 2 laboratories; however, the dismissible difference between laboratories $(0.4 \% \mathrm{OM})$ for $\mathrm{OMD}_{\mathrm{EDOM}}$ in this study agrees with 2 ring tests, each involving 4 laboratories, performed for concentrate ingredients (De Clerck, 2018, 2019). Compared with the rumen fluid method, the same tendency was found for reproducibility as for repeatability, where EDOM

Table 4. Models describing the relationship between observed digestible OM measured using the enzymatic digestibility of OM (EDOM) method (DOM $\mathrm{EDOM}_{\mathrm{M}} \%$ of DM) and various significant regressors: model A contains weighted sum of DOM $\mathrm{EDOM}\left(\mathrm{DOM}_{\mathrm{EDOM}} \mathrm{Add}\right)$; models $\mathrm{B}_{i}$ also contain effects of ingredients $\left[\mathrm{DOM}_{\mathrm{EDOM}}(\%\right.$ of DM) $\times$ share of ingredient in compound feed $(\%$ of $\mathrm{DM})]$

\begin{tabular}{|c|c|c|c|c|c|c|}
\hline Item & Models for $\mathrm{DOM}_{\mathrm{EDOM}}(\% \text { of } \mathrm{DM})^{1}$ & \multicolumn{3}{|c|}{ Model fit ${ }^{2}$} & \multicolumn{2}{|c|}{ Model prediction $^{3}$} \\
\hline A & $1.65+0.99 \mathrm{DOM}_{\mathrm{EDOM}} \mathrm{Add}$ & 0.93 & 1.09 & 157 & 61.04 & 0.93 \\
\hline $\mathrm{B}_{2}$ & $\begin{array}{l}0.94+0.99 \mathrm{DOM} \mathrm{EDOM}_{\mathrm{E}} \mathrm{Add}-0.01(\mathrm{SBM} \times \mathrm{Wh})+0.08 \mathrm{Wh}-0.001(\mathrm{Wh} \\
\times \mathrm{Ry} \times \mathrm{RSM})-0.04 \mathrm{RSM}+0.04 \mathrm{SBM}\end{array}$ & 0.95 & 0.98 & 163 & 55.28 & 0.94 \\
\hline $\mathrm{B}_{3}$ & $\begin{array}{l}0.11+1.00 \mathrm{DOM} \mathrm{EDOM}_{\mathrm{EDA}} \mathrm{Add}-0.01(\mathrm{SBM} \times \mathrm{Wh})+0.12 \mathrm{Wh}-0.001(\mathrm{Wh} \\
\times \mathrm{Ry} \times \mathrm{RSM})-0.04 \mathrm{RSM}+0.04 \mathrm{SBM}-0.01(\mathrm{Wh} \times \mathrm{SBP})+0.06 \mathrm{SBP}\end{array}$ & 0.96 & 0.93 & 163 & 48.93 & 0.94 \\
\hline
\end{tabular}

${ }^{1} \mathrm{DOM}_{\mathrm{EDOM}} \mathrm{Add}=$ digestible $\mathrm{OM}$ calculated by the weighted sum of ingredients; $\mathrm{SBM}=$ soybean meal; $\mathrm{Wh}=$ wheat; $\mathrm{RSM}=$ rapeseed meal; Ry $=$ rye; $\mathrm{SBP}=$ sugar beet pulp.

${ }^{2} \mathrm{RSE}=$ residual standard error of the model; $\mathrm{BIC}=$ Bayesian information criterion.

${ }^{3} \mathrm{PRESS}=$ predicted residual error sum of squares. 
showed lower variation of OMD between laboratories than did the rumen fluid methods for forages: 0.97 versus $2.33 \%$ OM (Søegaard et al., 2001) and 0.70 versus $2.10 \%$ OM (Weisbjerg et al., 2007).

A possible explanation for the higher precision (repeatability and reproducibility) of enzymatic methods might be the use of commercial enzymes and synthetic solutions that might translate into more stable results. In contrast, when rumen fluid is used, the stability of the solution might be compromised due to donor variation (Church and Petersen, 1960; Holden, 1999); therefore the method is difficult to standardize across multiple laboratories. On the other hand, a possible disadvantage of enzymatic methods could lie in the dependability of production of these enzymes from a third party. The importance of a precise method is that its precision makes it adoptable in practice, as this makes implementation of the method in different laboratories and regions worthwhile. Results from this study are of great importance for the use of EDOM, as this method could potentially be used in the NorFor system for compound feeds, expanding to other countries (it is already official in Denmark) and other regions using the system.

\section{Relation Between Ingredients and Compound Feeds}

Scarce literature exists on the additive properties of digestible organic matter. For ruminant feeds, Prestløkken (1999) found that effective protein degradability as predicted by the addition of ingredients overpredicted the values measured directly in the mix feeds by up to 5 percentage points. However, we found the contrary for $\mathrm{DOM}_{\mathrm{EDOM}}$ : additivity of $\mathrm{DOM}_{\mathrm{EDOM}}$ underpredicted the measured $\mathrm{DOM}_{\mathrm{EDOM}}$ of compound feeds by less than 1 percentage point $(0.83 \%$ DM, Figure $2 \mathrm{~b})$.

The effect of specific ingredients beyond additivity was identified for the relationship between ingredients and compound feeds (Table 4). However, the numerical magnitude of the effect of ingredients and their interactions was minor. The model considering only pure additivity showed the best fit with the lowest BIC (BIC = $157)$. Moreover, the prediction ability $\left(\bar{R}^{2}\right)$ showed minor improvement with the inclusion of ingredients. Further, it is not clear whether the effect of ingredients included in these models was due to intrinsic characteristics of the ingredients or to the proportions in which they were included in the compound feed, as the ingredients detected coincide with the most frequently used ingredients in the compound feed samples (Table 1). Our results suggest that $\mathrm{DOM}_{\mathrm{EDOM}}$ has an additive property. No evaluation of the effect of ingredients was performed for chemical components, as this was beyond the scope of the present study.

The high correlation between amounts of nutrients calculated from additivity of ingredients and amounts of nutrients measured directly in compound feeds agrees with the correlation found for $\mathrm{DOM}_{\mathrm{EDOM}}$. The $\mathrm{DOM}_{\mathrm{EDOM}}$, as well as the CFat, showed an average difference between calculated and measured values that accounted for $0.83 \%$ DOM in DM and $0.25 \%$ CFat in DM, respectively. Both errors are within the acceptable limits (5\% limit for $\mathrm{DOM}_{\mathrm{EDOM}}$ corresponds to the energy tolerance limit and 1\% CFat limits, respectively) established for compound feed declarations (European Commission, 2010). All chemical components presented linear bias, meaning that the prediction would have higher errors in extreme values. Despite this, the largest linear bias was reported for NDF $(2.01 \% \mathrm{DM})$ at the maximum predicted value $(36.2 \%$ of $\mathrm{DM})$, which is lower than the acceptable limit in EU regulations (3.5\%). Although all nutrients fell within the tolerance limits, the bias presented in this study should be taken as a guideline for the creation of compound feeds to match the targeted concentration of nutrients. Moreover, CFat presented the highest coefficient of determination between residuals and the predicted CFat content of compound feeds (Figure $5 \mathrm{~b}, \mathrm{R}^{2}=0.25$ ). This suggests greater overprediction of CFat by additivity of ingredients at higher CFat concentrations. Difficulties with extraction of CFat due to the diverse nature of the different components could be a potential explanation (Palmquist and Jenkins, 2003), although it is difficult to explain our finding of overestimation of CFat by additivity of ingredients.

To our knowledge, although the additive property has long been assumed in chemical components, no evidence supporting this assumption has been reported. Thus, the evaluation of additivity of the chemical parameters in this study is fundamental for several reasons. First, it is vital to evaluate and report the property's existence. Second, our study has allowed us to compare the additive property of the chemical components with the results of the $\mathrm{DOM}_{\mathrm{EDOM}}$ method, using additivity results from chemical components as reference, and to conclude whether $\mathrm{DOM}_{\mathrm{EDOM}}$ additivity could be potentially useful in practice. Moreover, validation of the assumption of additivity of the chemical components is central not only to the formulation of commercial compound feeds but also to research, where additivity of this parameters is commonly assumed. Our results suggest that chemical parameters are additive. Moreover, $\mathrm{DOM}_{\mathrm{EDOM}}$ additivity was comparable with the additivity of the chemical parameters, confirming the additive property for this parameter as well. 


\section{CONCLUSIONS}

The EDOM method showed high repeatability (ICC $=98.9 \%$ ) and reproducibility (ILC $=92.6 \%$ ) and is therefore a precise method for estimating OM digestibility in compound feeds. We found a high coefficient of determination $\left(\mathrm{R}^{2}=0.93\right)$ between $\mathrm{DOM}_{\mathrm{EDOM}}$ on compound feed and $\mathrm{DOM}_{\mathrm{EDOM}}$ measured in feed ingredients and weighted by the composition of ingredients in the compound feed. Therefore, the EDOM method showed a convincing additive property. Chemical components (CP, starch, CFat, and NDF) also showed additivity, with $\mathrm{R}^{2}$ ranging from 0.93 for NDF to 0.98 for starch. However, the bias shown in this study, especially for CFat, indicates that possible bias should be considered when formulating compound feeds to match target concentrations.

\section{ACKNOWLEDGMENTS}

For funding the project, the authors thank the Research Council of Norway (Oslo). For contributing the feed samples, the authors thank Lantmännen Lantbruk (Malmö, Sweden), Vallberga Lantmän (Vallberga, Sweden), Norgesfôr AS (Oslo, Norway), Felleskjøpet Agri (Vikersund, Norway), Fiskå Mølle AS (Tau, Norway), and DLG (Copenhagen, Denmark). The authors have not stated any conflicts of interest.

\section{REFERENCES}

Åkerlind, M., M. Weisbjerg, T. Eriksson, R. Tøgersen, P. Udén, B. L. Ólafsson, O. M. Harstad, and H. Volden. 2011. Feed analyses and digestion methods. Pages 41-54 in NorFor-The Nordic Feed Evaluation System. H. Volden, ed. Wageningen Academic Publishers, the Netherlands.

Allen, D. M. 1974. The relationship between variable selection and data augmentation and a method for prediction. Technometrics 16:125-127. https://doi.org/10.1080/00401706.1974.10489157 www.doi.org/10.2307/1267500.

Angkanaporn, K., V. Ravindran, and W. L. Bryden. 1996. Additivity of apparent and true ileal amino acid digestibilities in soybean meal, sunflower meal, and meat and bone meal for broilers. Poult. Sci. 75:1098-1103. https://doi.org/10.3382/ps.0751098.

Aufrère, J., and B. Michalet-Doreau. 1983. In vivo digestibility and prediction of digestibility of some by-products. Pages $25-33$ in Feeding Value of By-products and Their Use by Beef Cattle. V. Boucqui, L. O. Fiems, and B. G. Cottyn, ed. Commission of the European Communities Publishing, Brussels, Belgium.

Barber, G. D., D. I. Givens, M. S. Kridis, N. W. Offer, and I. Murray. 1990. Prediction of the organic matter digestibility of grass silage. Anim. Feed Sci. Technol. 28:115-128. https://doi.org/10.1016/ 0377-8401(90)90074-I.

Bartlett, J. W., and C. Frost. 2008. Reliability, repeatability and reproducibility: Analysis of measurement errors in continuous variables. Ultrasound Obstet. Gynecol. 31:466-475. https://doi.org/ 10.1002/uog.5256.

Bates, D., M. Mächler, B. Bolker, and S. Walker. 2015. Fitting linear mixed-effects models using lme4. J. Stat. Softw. 67:1-48. https:// doi.org/10.18637/jss.v067.i01.

Beecher, M., R. Baumont, J. Aufrère, T. M. Boland, M. O. Donovan, N. Galvin, C. Fleming, and E. Lewis. 2015. A comparison of two enzymatic in vitro methods to predict in vivo organic matter digestibility of perennial ryegrass. Livest. Sci. 177:33-42. https://doi .org/10.1016/j.livsci.2015.03.028.

Church, D. C., and R. G. Petersen. 1960. Effect of several variables on in vitro rumen fermentation. J. Dairy Sci. 43:81-92. https://doi .org/10.3168/jds.S0022-0302(60)90114-4.

de Boever, J. L., B. G. Cottyn, F. X. Buysse, F. W. Wainman, and J. M. Vanacker. 1986. The use of an enzymatic technique to predict digestibility, metabolizable and net energy of compound feedstuffs for ruminants. Anim. Feed Sci. Technol. 14:203-214. https://doi .org/10.1016/0377-8401(86)90093-3.

De Clerck, E. 2018. Rapportering af ringanalyse til beregning af energien i foder. M. o. F. Fødevarestyrelsen. Aarhus, Denmark (in Danish).

De Clerck, E. 2019. Rapportering af ringanalyse til beregning af energien i foder. M. o. F. Fødevarestyrelsen. Aarhus, Denmark (in Danish).

Dumas, J. 1831. Procedes de l'analyse organique. Ann. Chim. Phys. 247:198-213.

European Commission. 2009. Laying down the methods of sampling and analysis for the official control of feed. Off. J. Eur. Union L $52: 1-130$.

European Commission. 2010. Annex IV to Regulation (EC) No $767 / 2009$ on permitted tolerances for the compositional labelling of feed materials or compound feed as referred to in Article 11(5). Off. J. Eur. Union L 229:1-130.

Fan, M. Z., and W. C. Sauer. 2002. Additivity of apparent ileal and fecal phosphorus digestibility values measured in single feed ingredients for growing-finishing pigs. Can. J. Anim. Sci. 82:183-191. https://doi.org/10.4141/A01-072.

Gosselink, J. M. J., J. P. Dulphy, C. Poncet, M. Jailler, S. Tamminga, and J. W. Cone. 2004. Prediction of forage digestibility in ruminants using in situ and in vitro techniques. Anim. Feed Sci. Technol. 115:227-246. https://doi.org/10.1016/j.anifeedsci.2004 .01 .008 .

Holden, L. A. 1999. Comparison of methods of in vitro dry matter digestibility for ten feeds. J. Dairy Sci. 82:1791-1794. https://doi .org/10.3168/jds.S0022-0302(99)75409-3.

Iowerth, D., H. Jones, and M. V. Hayward. 1975. The effect of pepsin pretreatment of herbage on the prediction of dry matter digestibility from solubility in fungal cellulase solutions. J. Sci. Food Agric. 26:711-718. https://doi.org/10.1002/jsfa.2740260518.

Janč́k, F., M. Rinne, P. Homolka, B. Čermák, and P. Huhtanen. 2011. Comparison of methods for forage digestibility determination. Anim. Feed Sci. Technol. 169:11-23. https://doi.org/10.1016/. .anifeedsci.2011.05.003.

JCGM. 2012. International vocabulary of metrology - Basic and general concepts and associated terms. 3rd ed. No. 200:2012. Joint Committee for Guidelines of Metrology.

Menke, K. H., L. Raab, A. Salewski, H. Steingass, D. Fritz, and W. Schneider. 1979. The estimation of the digestibility and metabolizable energy content of ruminant feedingstuffs from the gas production when they are incubated with rumen liquor in vitro. J. Agric. Sci. 93:217-222. https://doi.org/10.1017/S0021859600086305.

Mertens, D. R., M. Allen, J. Carmany, J. Clegg, A. Davidowicz, M. Drouches, K. Frank, D. Gambin, M. Garkie, B. Gildemeister, D. Jeffress, C. S. Jeon, D. Jones, D. Kaplan, G. N. Kim, S. Kobata, D. Main, X. Moua, B. Paul, J. Robertson, D. Taysom, N. Thiex, J. Williams, and M. Wolf. 2002. Gravimetric determination of amylase-treated neutral detergent fiber in feeds with refluxing in beakers or crucibles: Collaborative study. J. AOAC Int. 85:1217-1240.

Palić, D. V., and K. J. Leeuw. 2009. Comparison of three in vitro methods for determining and predicting the organic matter digestibility of complete diets for ruminants. Acta Periodica Technologica 40:79-86. https://doi.org/10.2298/APT0940079P.

Palmquist, D. L., and T. C. Jenkins. 2003. Challenges with fats and fatty acid methods. J. Anim. Sci. 81:3250-3254. https://doi.org/ $10.2527 / 2003.81123250 x$.

Parker, A. E., M. A. Hamilton, and D. M. Goeres. 2018. Reproducibility of antimicrobial test methods. Sci. Rep. 8:12531. https://doi .org/10.1038/s41598-018-30282-3. 
Prestløkken, E. 1999. In situ ruminal degradation and intestinal digestibility of dry matter and protein in expanded feedstuff. Anim. Feed Sci. Technol. 77:1-23. https://doi.org/10.1016/S0377 -8401(98)00246-6.

R Core Team. 2019. R: A Language and Environment for Statistical Computing. R Foundation for Statistical Computing, Vienna, Austria.

Søegaard, K., M. R. Weisbjerg, R. Thøgersen, and M. Mikkelsen. 2001. Laboratoriemetoder til bestemmelse af fordøjelighed i grovfoder til kvæg med særlig vægt på stivelsesholdige helsædsafgrøder. Foulum, Denmark (in Danish). Accessed Aug. 10, 2019. https://pure .au.dk/ws/files/458515/djfhd34.pdf.

St-Pierre, N. R. 2003. Reassessment of biases in predicted nitrogen flows to the duodenum by NRC 2001. J. Dairy Sci. 86:344-350. https://doi.org/10.3168/jds.S0022-0302(03)73612-1.

Stoffel, M. A., S. N. Nakagawa, and H. Schielzeth. 2017. rptR: Repeatability estimation and variance decomposition by generalized linear mixed-effects models. Methods Ecol. Evol. 8:1639-1644. https: //doi.org/10.1111/2041-210X.12797.

Taylor, B. N., and C. E. Kuyatt. 1994. NIST Technical Note 1297: Guidelines for Evaluating and Expressing the Uncertainty of NIST Measurement Results. National Institute of Standards and Technology, Gaithersburg, MD.

Tilley, J. M. A., and R. A. Terry. 1963. A two-stage technique for the in vitro digestion of forage crops. Grass Forage Sci. 18:104-111. https://doi.org/10.1111/j.1365-2494.1963.tb00335.x.

Volden, H. 2011. NorFor - The Nordic Feed Evaluation System. 1st ed. Wageningen Academic Publishers, Wageningen, the Netherlands.
Weisbjerg, M. R., and T. Hvelplund. 1993. Bestemmelse af nettoenergiindhold (FEK) i råvarer og kraftfoderblandinger: Report no. 3. S. Husdyrbrugsfors $\varnothing$ g. Tjele, Denmark (in Danish).

Weisbjerg, M. R., and T. Hvelplund. 1996. The use of enzymatic solubility for the prediction of organic matter digestibility of compounded feedstuff. Pages 99-102 in Proc. in Vitro and in Vivo Methods Used in Experiments on Digestion Processes and Feed Evaluation. The Kielanowski Institute of Animal Physiology and Nutrition, Polish Academy of Sciences, Krakow, Poland.

Weisbjerg, M. R., K. Søegaard, R. Thøgersen, M. Mikkelsen, and G. Brunsgaard. 2007. Bestemmelse af fordøjelighed af organisk stof i grovfoder ved brug af in vitro-metoder baseret på vomvæske eller enzymer: DJF Husdyr Report no. 76. Foulum, Denmark (in Danish).

Xue, P. C., D. Ragland, and O. Adeola. 2014. Determination of additivity of apparent and standardized ileal digestibility of amino acids in diets containing multiple protein sources fed to growing pigs. J. Anim. Sci. 92:3937-3944. https://doi.org/10.2527/jas.2014 -7815 .

\section{ORCIDS}

C. Álvarez @i https://orcid.org/0000-0001-7300-6831

E. Prestløkken ® https://orcid.org/0000-0003-3151-6782

H. Volden (ㄱ https://orcid.org/0000-0002-5790-2086

M. R. Weisbjerg () https://orcid.org/0000-0002-6514-9186 